\title{
Nueva polémica en torno a la deuda agraria
}

La historia de la tierra en El Salvador está plagada de abusos que, incluso, han Ilegado, en varias ocasiones, hasta la expropiación forzosa. La situación del agro ha sido de permanente crisis para el campesino y, más recientemente, hasta de los grandes productores agropecuarios. Lógicamente esta situación ha devenido en una marcada caída en la importancia del Producto Interno Bruto (PIB) Agropecuario al grado que, desde 1970, el aporte del sector agropecuario al Producto Interno Bruto total ha caído desde el 25.35 por ciento hasta menos del 14 por ciento, en 1996; asimismo, los censos poblacionales reflejan que entre 1971 y 1992, la población rural de El Salvador tuvo del 61 al 49 por ciento. Estos datos reflejan con claridad la presencia de una ingente crisis económica y social en el agro.

Ante esta realidad, han surgido propuestas de reactivación integral del agro provenientes tanto del sector gubernamental como de otras instancias no gubernamentales; así como decretos de menores aspiraciones, pero significativos, mediante los cuales se han suspendido los embargos resultantes de la deuda agraria (conocidos como decretos 698 y 699) y se ha condonado hasta un 70 por ciento de la deuda agraria de las cooperativas del sector reformado a cambio del "pronto pago" del 30 por ciento restante.

La propuesta más reciente ha sido la condonación total de la deuda agraria, la cual incluye las deudas de diversos tipos de productores agrícolas, entre los cuales destacan tanto cooperativas del sector reformado como productores individuales y asociaciones anónimas. Este tema ha ocupado las primeras discusiones de la nueva asamblea legislativa instalada en mayo pasado; aunque cabe seña- lar, empero, que esta polémica no es nueva y se remonta prácticamente a inicios de la presente década con la profundización de la crisis del agro.

Como era de esperarse, esta discusión ha abierto el debate sobre la pertinencia de la condonación de la deuda; sus detractores - entre los cuales se cuentan gremiales empresariales y el mismo gobiernoargumentan que la condonación de la deuda agraria beneficiaría a un grupo reducido de la población, a costa del aporte de otros sectores económicos. En cambio, diputados de los partidos de oposición en la asamblea legislativa han coincidido en señalar la importancia de condonar la deuda para aliviar la crisis económica del agro. Por el momento, los embargos derivados de la deuda agraria han sido suspendidos, mientras una subcomisión de la asamblea legislativa realiza un estudio sobre la pertinencia -o impertinencia - de la condonación de la deuda. Los resultados del estudio deberían estar listos para mediados de julio de 1997.

A continuación se presenta una breve reseña sobre el problema de la tierra en El Salvador, lo cual es fundamental para aclarar cuales son los orígenes de la propiedad de la tierra y como estos se relacionan con los problemas actuales. En forma adicional se busca presentar algunas características de la deuda agraria, en especial de la contraída con el Fondo de Saneamiento y Fortalecimiento Financiero (FOSAFFI), por ser la que más refleja - por el momento- la concentración de la deuda del sector agropecuario en un grupo minoritario. Posteriormente, se presentan algunas valoraciones en torno a la condonación de la deuda para finalizar con algunas sugerencias para enfrentar no sólo el problema de la deuda sino también el de la prolongada crisis del sector agropecuario. 
Durante la época colonial se implantó la utilización de la tierra para cultivos de agroexportación (cacao y añil) y, desde entonces, la propiedad de la tierra se definió exclusivamente en función de la fuerza; las tierras fueron asignadas por las autoridades coloniales por decreto, aunque ello implicara el despojo o, bien, la expulsión de comunidades indigenas que trabajaban las mismas tierras desde miles de años antes. De manera paradójica, los despojos de tierras en la época colonial no fueron, en realidad, tan drásticos y, al momento de la independencia, las comunidades indígenas aún contaban con una importante extensión de tierras comunales y ejidales a partir de las cuales se procuraban su subsistencia.

Después de la independencia, y con la introducción del cultivo del café, se registraron los mayores despojos de tierras y se generaron las condiciones que explican la proliferación de la pobreza en el país. De acuerdo con recopilaciones históricas, con la introducción del café, a partir de la segunda mitad del siglo XIX, hubo necesidad de utilizar las tierras altas de la cordillera central porque eran las más apropiadas para el cultivo del café. Debido a que la mayor parte de estas tierras se encontraba en manos de comunidades indígenas, se emitieron disposiciones legislativas que avalaron el despojo de estas tierras para utilizarlas principalmente al cultivo del café.

Por lo general, estas tierras fueron distribuidas entre las familias prominentes y los allegados del gobierno, a ello le siguieron patrones de una elevada concentración en la propiedad de la tierra, lo cual provocó una fuerte liberación de la población rural que de manera repentina se encontró sin más medio de subsistencia que su propia fuerza de trabajo. En este momento se inició el proceso de campesinización de la población rural e, incluso, de la migración campo-ciudad pero, sobre todo, se crearon las condiciones para el surgimiento de una sociedad con altas desigualdades: por un lado, el sector terrateniente que controla las mejores tierras del país y usufructúa los productos de cultivos de exportación -especialmente el café$y$, por el otro, el sector campesino, sin tierras, que además percibe salarios muy por debajo del costo de la canasta de alimentos.

En épocas recientes, la problemática en tomo a la concentración de la propiedad de la tierra llevó a considerar - sin mayores consecuencias- la implementación de la reforma agraria, en 1976.
Posteriormente, se ejecutó un programa de reforma agraria, a partir de 1980 , con el cual se alteró, aunque no de manera sustancial, la propiedad de la tierra.

A partir de la reforma agraria de los 80 surgió el término de "deuda agraria". Este término hacía referencia a los montos adeudados por el Instituto Salvadoreño de Transformación Agraria (ISTA) a los ex propietarios de las haciendas del sector reformado. Asombrosamente, la propuesta de condonación de la deuda agraria, en la actualidad en estudio por la asamblea legislativa, ha incluido casi todo tipo de créditos bancarios otorgados al sector agropecuario desde 1970.

El término deuda agraria se ha ampliado, es decir, no sólo comprende las deudas del sector reformado con el Instituto Salvadoreño de Transformación Agraria, sino también, como se mencionó al principio, las deudas del citado sector con el sistema financiero formal e, incluso, las de agentes productores del agro que no necesariamente son beneficiarios del proceso de reforma agraria pero, al igual que el sector reformado, se encuentran en siluación de mora bancaria. No sería de extrañar que entre estos sectores se encuentren grandes terratenientes que emergieron a partir del despojo y reparto de tierras organizado por el Estado para el cultivo del café.

El secreto bancario ha sido un obstáculo tradicional para analizar la composición de la deuda aunque, de acuerdocon informaciones vertidas por fuentes periodísticas que no han sido desmentidas por fuentes oficiales, parece claro que en los montos que se pretenden condonar se incluyen deudas de agentes productivos de alta capacidad económica. Dentro de la deuda agraria se encuentran los montos otorgados a través del FOSAFFI, los cuales totalizan 770.55 millones de colones, de los cuales 4.6 por ciento de los deudores debe 55.1 por ciento del total, mientras que el 95.4 por ciento restante debe el $\mathbf{4 4 . 9}$ por ciento. Los montos de las deudas individuales oscilan entre $\operatorname{los} 31$ y 10 millones de colones, y la mayoría se utilizó para el cultivo del café.

Por otra parte, la deuda del sector reformado comprendería un total aproximado de $1,461.2 \mathrm{mi}$ llones de colones, de los cuales sólo el 5.7 por ciento corresponde a la deuda del sector con el Instituto Salvadoreño de Transformación Agraria; el restante comesponde a deudas adquiridas con el 
sistema financiero formal para impulsar la producción en las tierras afectadas por la reforma agraria; los cuales, aparentemente, han resultado poco exitosos.

Las apreciaciones de los sectores políticos, en torno a la problemática de la deuda, han variado desde posturas que avalan la condonación total hasta otras que no la aprueban. Quienes están de acuerdo con esta última postura son los miembros del Comite Económico del gobierno, como el Ministro de Hacienda, el Ministro de Agricultura y el Vicepresidente del Banco Central de Reserva, pues para ellos es clara la inconveniencia de la condonación total de la deuda. En cambio, la mayor parte de las fracciones legislativas, o al menos las mayoritarias, coincide en la necesidad de condonar la deuda.

De acuerdo con el Ministro de Hacienda, Enrique Hinds, la condonación de la deuda afectaría al secior financiero y desestimularía el otorgamiento de créditos; al mismo tiempo sostiene que tendría un impacto inicial en las finanzas públicas de aproximadamente 1,400 millones de colones. Asimismo afirmó que se enfrentarían problemas de déficit fiscal, mayor inflación, deterioro en la balanza de pagos, escasez de créditos, alzas en las tasas de interés, etc.

Por su parte, el Ministro de Agricultura y Ganadería, Ricardo Quiñonez, también considera que la condonación de la deuda provocaría escasez del crédito y mayor inflación; pero a la vez consideró que existen casos en los cuales no se justifica el pago de la deuda, pues "El caso es que los más ricos, los que tienen mejores tierras son los que tienen más acceso a estos medios y han hecho este alboroto". Según Quiñonez, una solución viable podría consistir en financiar el pronto pago a un total aproximado de 103 cooperativas "con tierras pobres y quebradas" convirtiéndolas en sujetos de crédito y supervisando los financiamientos.

Por otro lado, el Vicepresidente del Banco Central de Reserva, Gino Bettaglio, considera que el problema del agro no va a solventarse con la condonación de la deuda sino solamente con la reactivación del sector. Afirmó que: "Se deben evitar las pérdidas fiscales y la politización del crédito agropecuario", y agregó "Sabemos de cooperativas que tienen la capacidad de pago, que tienen depositado en los bancos ganando más intereses".
Por su parte, las fracciones legislativas mayoritarias en la asamblea han mostrado una clara inclinación hacia la condonación de la deuda, aunque con diferentes enfoques. El Partido de Conciliación Nacional, por un lado, se inclina por condonar pequeñas deudas y cobrar grandes deudas que no fueron utilizadas para rubros agrícolas. El Frente Farabundo Martí para la Liberación Nacional se inclina por una condonación total de la deuda para estimular la reactivación del agro. El partido Alianza Republicana Nacionalista apoyaría la condonación si ésta no supondría que los beneficiarios quedaran excluidos de la lista de personas sujetas de crédito.

Llama la atención el hecho de que para el FMLN, la condonación de la deuda podría constituirse en un elemento que apuntale la recuperación del sector agropecuario pero, en realidad, esto no es así. Al examinar este problema, no puede perderse de vista el hecho de que la deuda agraria ha resultado de la profundización de la crisis económica en el agro y la consecuente insolvencia financiera del sector. Por tanto, para prevenir un nuevo problema de deuda agraria es necesario pri-

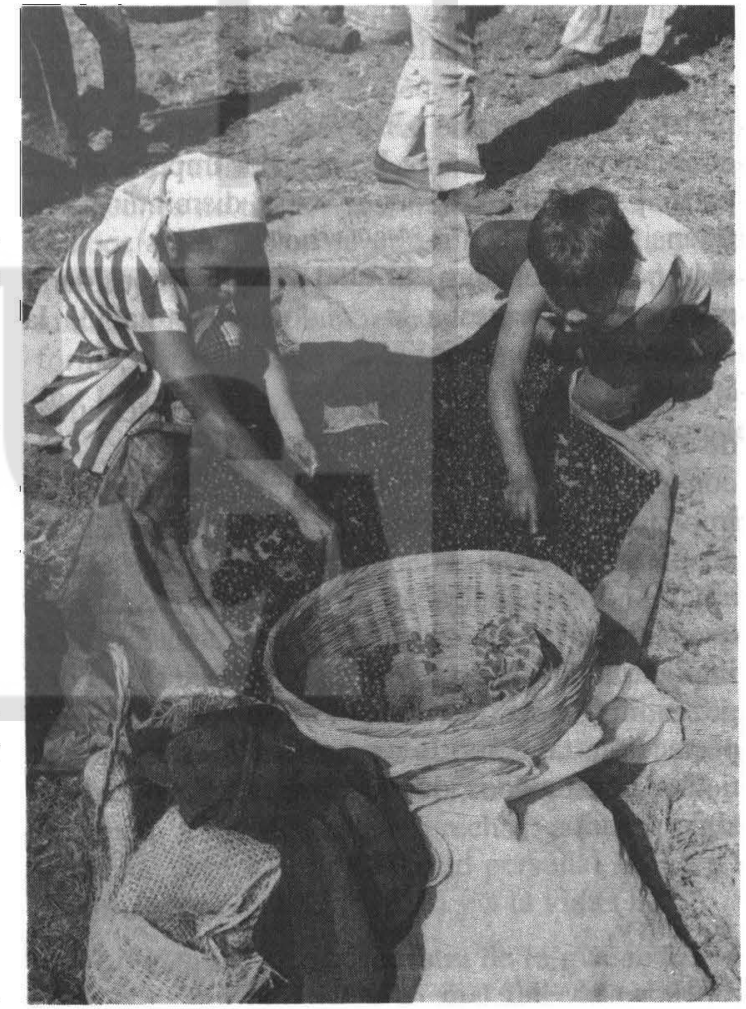


mero superar la crisis económica del agro. La profundización de la guerra, a partir de la década de 1980 - que tuvo como principal escenario el área rural-, la inadecuada administración de las propiedades comprendidas dentro del proceso de reforma agraria y, más recientemente, la implementación de políticas económicas neoliberales son los principales factores que explican la profunda crisis actual del sector agropecuario. Una vez finalizada la guerra, los dos principales problemas que enfrenta el agro son los dos últimos.

Mientras las implicaciones de estos elementos no sean contrarrestadas por una política diseñada en forma ad hoc para el sector agropecuario, difícilmente podría esperarse que con la sola condonación de la deuda se lograría la reactivación integral del sector agropecuario. Algunos aspectos que es necesario atender, y que las políticas neoliberales descuidan, son la imposibilidad de mejorar la competitividad de las exportaciones, la reducción del Estado, la reducción de los aranceles, el agotamiento de los recursos naturales y el difícil acceso a los mercados externos.

La condonación de la deuda por sí misma no es garantía de que se superarán los más ingentes problemas que enfrenta el agro; sólo la acción decidida del gobierno para favorecer a este sector podría garantizar una verdadera recuperación de la economía agropecuaria. Lo anterior implica que la participación del Estado, lejos de disminuir, debe intensificarse y centrar su atención en los sectores más pobres del agro, lo cual implica considerar opciones diferentes a la condonación total de la llamada deuda agraria.

Una revisión de las principales características de la deuda muestra con claridad meridiana la inconveniencia de una condonación total, pues ello implicaría una nueva instrumentalización del Estado para beneficio económico de sectores que, de antemano, concentraban buena parte de lo que quedaba de la riqueza rural. La condonación total implicaría que el Estado favoreciera a sectores que gozan, desde el siglo pasado, de su benevolencia y protección, tal como lo evidencian los despojos de tierras consumados durante la segunda mitad del siglo pasado.
Una propuesta más sensata sería la condonación de la deuda sólo para las cooperativas y, si los hay, propietarios individuales beneficiarios del proceso de reforma agraria y en situación de mora bancaria. Lo anterior implicaría excluir del programa a los grandes propietarios de tierras que han contraído fuertes deudas con el sistema financiero, en muchos casos para fines diferentes a la agricultura. A este efecto resulta ilustrativo el caso de la deuda FOSAFFI reseñado arriba, donde más de la mitad de la deuda es atribuible a un porcentaje minoritario del total de deudores.

La reforma agraria perseguía cambiar la injusta distribución de la tierra prevaleciente en el país y, por ello, contemplo la asignación de tierras a grupos cooperativos o personas naturales sin tierras. Desde su ejecución, no podría decirse que la situación de los beneficiarios ha cambiado drásticamente, estos continúan integrando los grupos más pobres del área rural y, en esa medida, se justifica que el gobierno adopte medidas para aliviar su situación. Más aún, si se considera que uno de los objetivos confesos del gobierno es la reducción de la pobreza.

Lo anterior no obsta, empero, para que aún dentro del mismo grupo de beneficiarios de la reforma agraria se discrimine entre aquellos que definitivamente no pueden pagar y aquellos que sí tienen capacidad de pago. Estos últimos podrían acogerse al decreto que permite la condonación a cambio del "pronto pago" del 30 por ciento del monto total de sus deudas.

Al considerar estas alternativas frente a la condonación total de la deuda, también se estaría reduciendo grandemente los posibles efectos macroeconómicos asociados a la condonación de la deuda (déficit fiscal, inflación, déficit externo, alza de tasas de interés, etc.) y, al mismo tiempo, se estarían compensando - aunque sea en una minima proporción- los despojos históricos de tierras que, en última instancia, explican las profundas desigualdades económicas y sociales que caracterizan a la población del país.

Luis E. Romano Martínez 